\title{
GEOLOGIA E HIDROGEOLOGIA DA REGIÃO DO DISTRITO DE LAGOA BRANCA, CASA BRANCA, SP, APLICAÇÃO DE SONDAGEM ELETRICA. (*)
}

\author{
Adonis de SOUZA ** \\ André DAVINO ** \\ Carlos de Carvalho TORRES *** \\ Marcos MASSOLI *** \\ Osmar SINELLI ** \\ Percy Corrêa VIEIRA ***
}

\begin{abstract}
RESUMO
Quando da locação de novo ponto para perfuração de poço tubular profundo no Distrito de Lagoa Branca, utilizou-se o método das sondagens elétricas. (Afloram 1a área pesquisada, sedimentos cenozóicos de pequena espessura e sedimentos da Formação Aquidauana, representados localmente por siltitos argilosos e arenitos sílticos, de cores predominantemente avermelhadas. Os dados fornecidos pela interpretação de oito sondagens elétricas efetuadas e os dados obtidos de poços profundos perfu. rados nas imediações, levaram à definição de um lacólito subaflorante no Distrito de Lagoa Branca. Enfatiza-se a importancia da grande percentagem de ocorrência de diabásio na área, sobre a pequena percentagem de extrusivas (basalto).
\end{abstract}

\section{ABSTRACT}

In the location of a new place to the construction of a tubular deep well for underground water captation in Lagoa Branca district, SP, it was utilized the eletrical resistivity method.

The geologic features of this area, are comprised of cenozoic sediments of low thickness and sediments of "Aquidauana Formation", which are represented by argillaceous silts and siltics sandstones, with reddish colour.

The data obtained by the interpretation of eight electric drilling, realized in the area and the data obtained by the deep well drilled in the vicinity, led us to a definition of a sub-surface laccolith in Lagoa Branca district, SP.

We can enfasize the occurrence of a great percentual of diabase over the few percentual of basalt.

\section{INTRODÚÇÃO}

Um dos problemas fundamentais da prospecção geológica na borda da Bacia Sedimentar do Paraná é a presença e distribuição espacial dos diabásios, termos intrusivos da ampla manifestação de vulcanismo cretácico, aí ocorrido.

Dada sua extensão em superfície e subsuperfície, muitas vezes tais rochas foram tomadas como basaltos, e assim descritas e mapeadas. As observações mais recentes conduzem a considerar que a fase extrusiva do citado vulcanismo raramente se manifesta na região em esudo. DAVINO (1980) descreve em pormenores, a partir dos resultados de sondagens elétricas, o "Lacólito de Tambaú" (SP), denominado pseudo-cuesta, expressão topográfica resultante da erosão dessas estruturas. Trata-se, por con-

\footnotetext{
* Feito com auxílio da FAPESP (Processos 81/0045, 81/0044, 81/0041).

* Geologia - FFCL - USP Av. dos Bandeirantes, s/n..$^{\circ}$ - 14.100 Ribeirão Preto, SP, Brasil.

*** Instituto Geológico — Caixa Postal 8772 — 01000 São Paulo, SP, Brasil
} 
seguinte, de rochas intrusivas e não de basaltos.

No presente trabalho, a partir igualmente de sondagens elétricas e dados de poços, foi possível definir um lacólito subaflorante em Lagoa Branca (figs. 1 e 2), Município de Casa Branca, SP., localizado a cerca de $30 \mathrm{~km}$ a $\mathrm{SE}$ do acima referido lacólito de Tambaú (fig. 3, perfil AB). Os demais afloramentos de diabásio, em vista desses fatos, foram da mesma forma, interpretados, ainda que precariamente, como expressões isoladas ou setores de corpos de forma lacolítica.

\section{GEOLOGIA}

A região do Distrito de Lagoa Branca é composta por sedimentos da Formação Aquidauana, em grande parte capeada por depósitos cenozóicos. Intrusões de diabásio ocorrem notadamente a S-SE e a W-NW. O Embasamento Cristalino aparece a cerca de $15 \mathrm{~km}$ a leste do Distrito, e a Formação Corumbataí ocorre a cerca de $35 \mathrm{~km}$ a oeste.

O termo Formação Aquidauana foi utilizado pela primeira vez por LISBOA (1909) apud FIORI \& LANDIM (1980), para designar sedimentos vermelhos que ocorrem no flanco oeste da Bacia do $\mathrm{Pa}$ raná, no vale do Rio Aquidauana, Mato Grosso do Sul. ALMEIDA \& BARBOSA (1953) e ALMEIDA (1954) admitiram sua presença também na borda leste da bacia. ALMEIDA (op cit.) reconheceu a "extensão da Série Aquidauana ao interior do Estado de São Paulo, onde atinge pelo menos a região de Casa Branca".

Essa Formação é permo-carbonífera, tendo sido depositada nos ambientes glacial, periglacial, flúvio-lacustre e, subordinadamente, eólico (este último ambiente, segundo BJORNBERG et alii, (1965).

$\mathrm{Na}$ região de Lagoa Branca, o Aquidauana compõe-se, basicamente, de siltitos argilosos e arenitos sílticos (classificação essa segundo o diagrama triangular de Shepard). Suas cores são avermelhadas, mais raramente amareladas e esbranquiçadas. O grau de seleção indica tratar-se de sedimentos pobremente selecionados. As estruturas sedimentares mais comuns são a maciça e a estratificação plano-paralela.
Subordinadamiente ocorrem diamictitos e ritmitos. Os diamictitos são avermelhados, com seixos de quartzo e rochas cristalinas em meio a matriz areno-argilosa. Os ritmitos são constituídos por arenitos finos, maciços, de cor amarelo-esbranquiçada, intercalados a siltitos argilosos, avermelhados, com acamamento plano-paralelo.

O contato basal da Formação Aquidauana se dá através de uma discordância erosiva esculpida sobre o Embasamento Cristalino, representado na região por rochas migmatíticas.

Depósitos cenozóicos campeiam essa Formação tanto nos espigões como nas encostas e nos vales, apresentando uma topografia bastante suave. São constituídos por areias argilosas muito pobremente selecionadas, sem apresentar qualquer tipo de estrutura sedimentar, cor vermelho-amarelada, apresentando geralmene na base uma linha de seixos ou cascalheira, composta principalmente por quartzo. A espessura desses sedimentos varia de alguns decímetros a cerca de 20 metros.

Sedimentos recentes ocorrem ao longo das drenagens principais, constituindo depósitos de planície de inundação.

$\mathrm{Na}$ figura " 2 " representa-se o mapa geológico da sede do Distrito de Lagoa Branca e na figura " 3 " os perfís geológicos da Folha de Casa Branca.

Lagoa Branca localiza-se entre duas grandes intrusões de diabásio (fig. 3, perfil CD): uma, situada na região de Santa Cruz das Palmeiras, a oeste, posicionada no contato entre a formação Corumbataí e o grupo Tubarão, e a outra, localizada entre Aguaí e São João da Boa Vista, a leste no contato do Tubarão com o Embasamento Cristalino.

Intrusões de diabásio do tipo descrito ocorrem a sul do Distrito, posicionadas estratigraficamente na porção mediana da Formação Aquidauana (fig. 3, perfil EF)

\section{HIDROGEOLOGIA}

O Instituto Geológico realizou estudos hidrogeológicos no Disrito de Lagoa Branca, com a finalidade de solucionar o problema de abastecimento, cuja necessidade é avaliada em $10.000 \mathrm{l} / \mathrm{h}$. 
O abastecimento era precário e feito por meio de duas cisternas de 15 a $25 \mathrm{~m}$ de profundidade, que exploram o lençol freático. Um primeiro poço perfurado atingiu diabásio (vide fig. 2, poço junto à Escola) aos 25 metros. Em vista de ser sempre visível a distribuição espacial dessas intrusões, conforme constatação das pesquisas mais recentes, resolveu-se realizar um estudo mais amplo por sondagens elétricas, por ser este um dos métodos já consagrados para a resolução desse tipo de problema.

Os aqüíferos exisentes na área pesquisada são essencialmente de dois tipos: a) aqüíferos freáticos - das Formações superficiais (o Cenozóico, o diabásio decomposto e fraturado e mesmo o regolito do Grupo Tubarão); b) aqüífero Tubarão, correspondente aos sedimentos do Grupo de mesmo nome.

Os primeiros, pouco conhecidos, são irregulares e suscetíveis à poluição, enquanto o aqüífero Tubarão é bem mais conhecido e estudado MEZZALIRA \& TORRES (1977), apresentando o seguinte comportamento hidrogeológico estatístico: $26,33 \%$ - poços ruins; $26,33 \%$ - poços razoáveis; $24,69 \%$ - poços bons; e $22,65 \%$ - poços ótimos.

Optou-se por explorar o aqüífero Tubarão, para o que o ideal seria a construção de um poço tubular profundo que atravessasse a maior espessura desse Grupo, evitando a presença de diabásio.

\section{SONDAGENS ELETRICAS}

Foram executadas oito sondagens elétricas (figs. 4 e 5), com $\mathrm{AB}$ de 400 a 1000 metros, tendo sua interpretação permitido delimitar a "projeção horizontal do topo subaflorante do diabásio de Lagoa Branca" (fig. 2) e igualmente avaliar a atitude provável do Embasamento Cristalino (fig. 3).

As S. E. n. ${ }^{\text {os }} 1,2 \quad 3$ atingiram o diabásio; as demais, atravessaram grandes espessuras de sedimentos do Grupo Tubarão, da ordem de 300 a 400 metros, surpreendentemente grandes para a região pesquisada.

\section{CONCLUSÕES}

1) A localização do poço de captação obedeceu a dois critérios: a) atingir a espessura máxima de sedimentos, evitando-se o diabásio; b) situar-se o mais próximo possível da área urbana (fig. 2).

2) É preciso enfatizar a importância de se distinguirem estruturas intrusivas (diabásio), das extrusivas (basaltos) nas pesquisas de água subterrânea. As sondagens elétricas, de fácil execução e baixo custo operacional, constituem até o presente $o$ melhor, senão o único, método de prospeç̧ão. Na fig. 2, pode-se considerar como área de risco para a prospecção de água subterrânea todo o setor hachurado, praticamente coincidente com a área urbana de Lagoa Branca.

3) O fato do Embasamento Cristalino situar-se até $400 \mathrm{~m}$ de profundidade, ou seja, $350 \mathrm{~m}$ de altitude sobre o nível do mar, pode constituir um argumento a favor de uma hipótese sobre a natureza tectônica, por falhamentos, da chamada "Depressão Periférica" (FREITAS, R. O. de - comunicação verbal).

4) As pesquisas geológicas sobre a distribuição espacial dos diabásios devem prosseguir. A hipótese mais simples de que constituem principalmente lacólitos é apenas preliminar. Outras formas certamente ocorrem.

\section{AGRADECIMENTOS}

Agradecemos à FAPESP pelo auxílio concedido para a realização do presente trabalho. Ao Dr. Ruy Osório de Freitas nossa gratidão, pela revisão geral do texto e pelas críticas recebidas. Ao Dr. Sérgio Mezzalira, Diretor do Instituto Geológico, pelo constante incentivo ao desenvolvimento das pesquisas do Instituto Geológico. 
Rev. IG, São Paulo, 3(1):15-23, jan./jun. 1982

MAPA DE LOCALIZAÇÃO DE LAGOA BRANCA E SEÇÕES GEOLÓGICAS

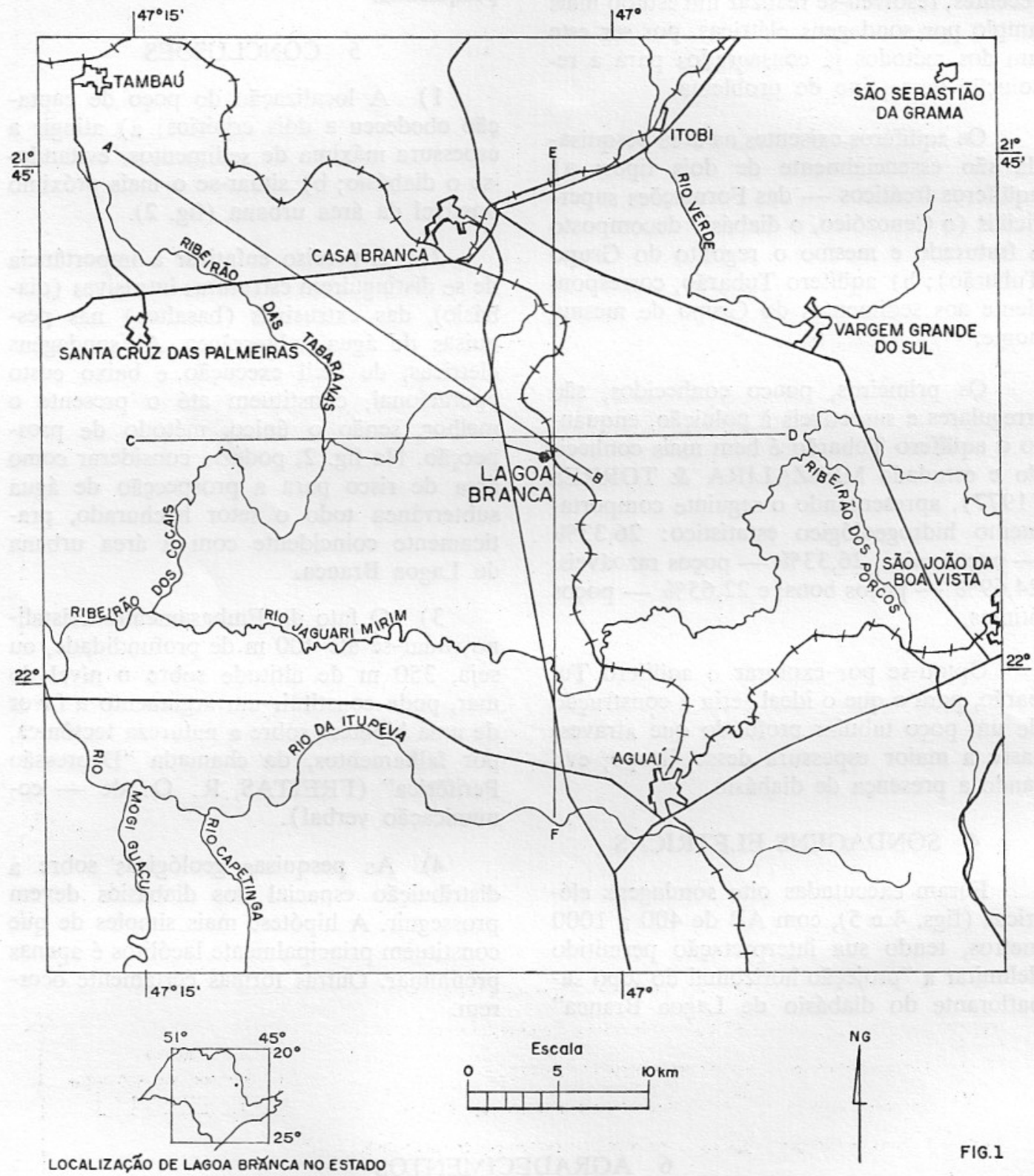


Rev. IG, São Paulo, 3(1):15-23, jan./jun. 1982

\section{MAPA GEOLÓGICO DOS ARREDORES DE LAGOA BRANCA}
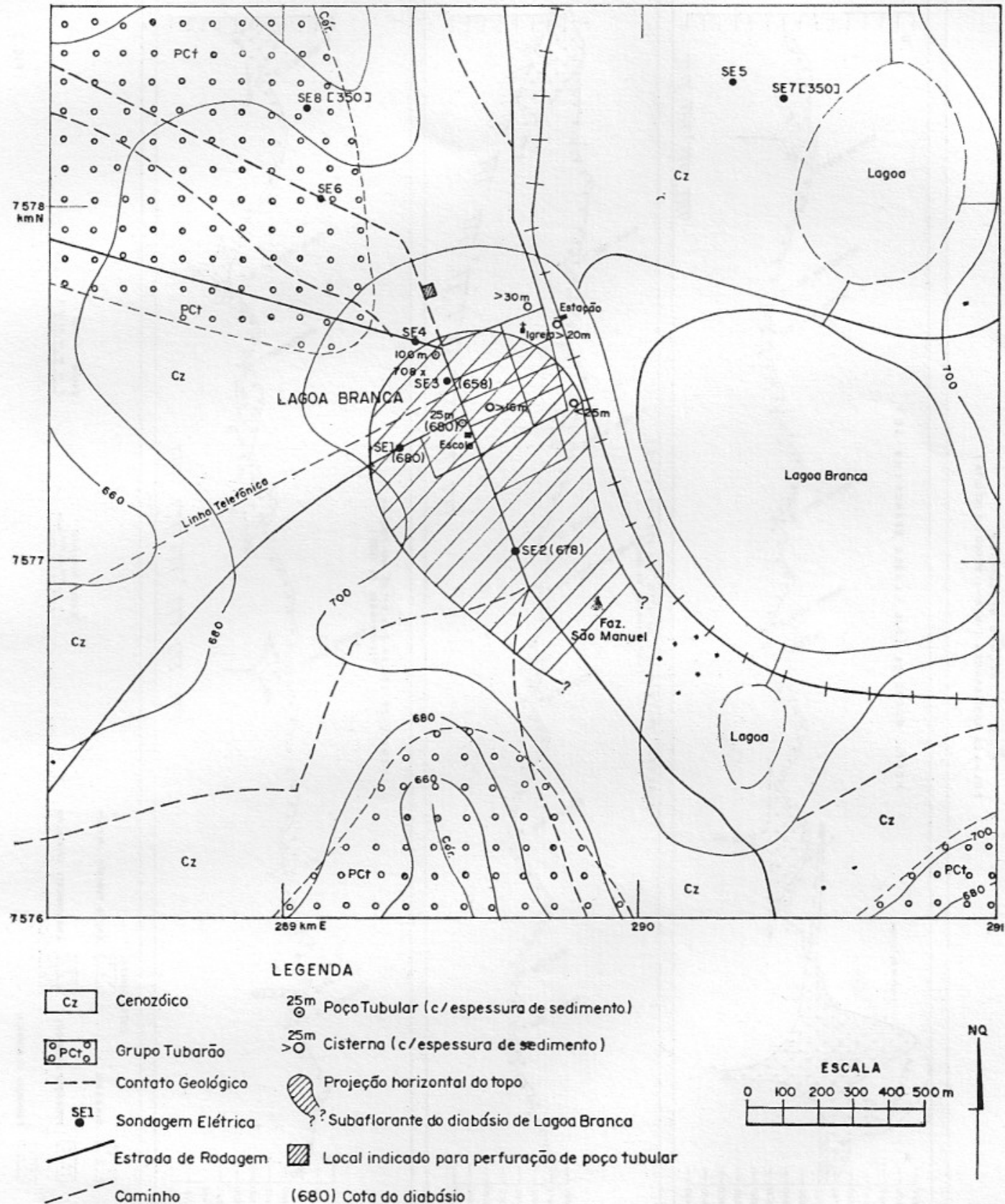

Estrodo de Ferro [350] Coto do embosomento

FIG. 2 

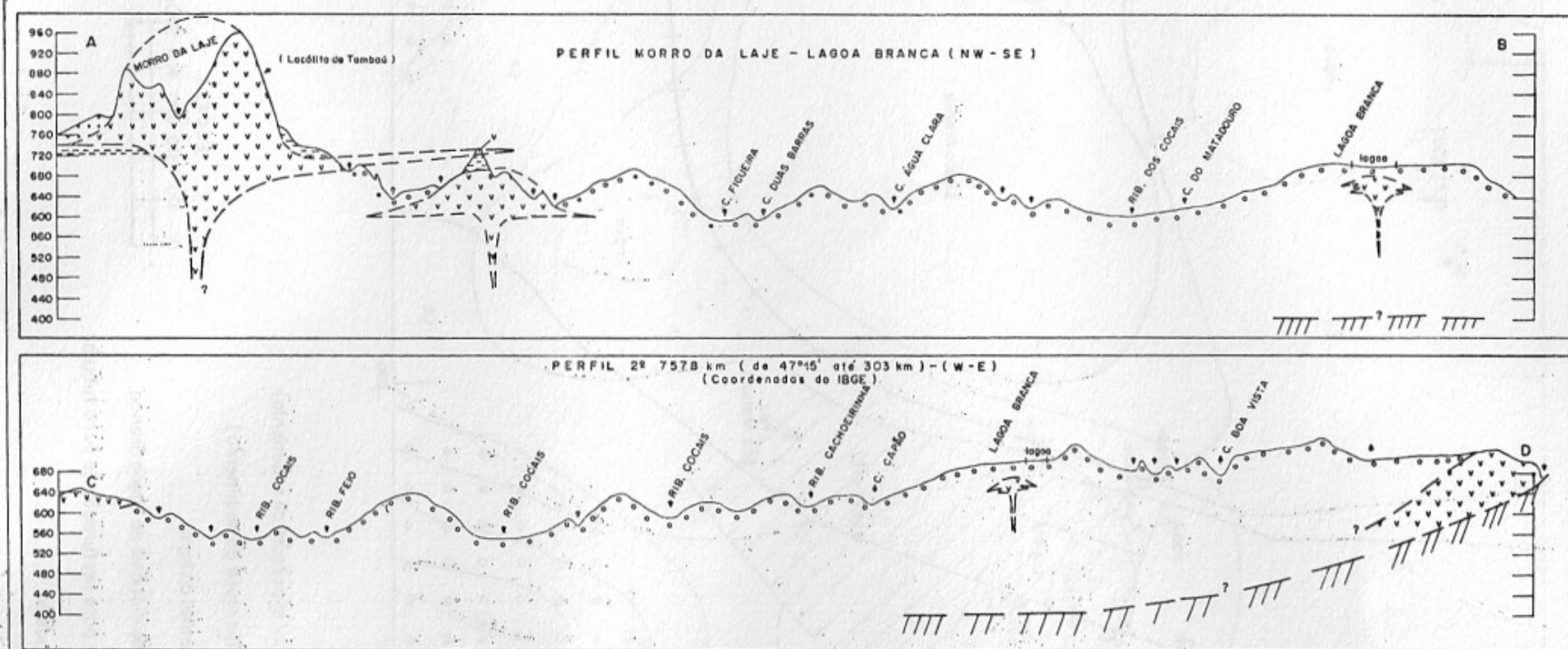

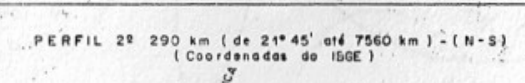

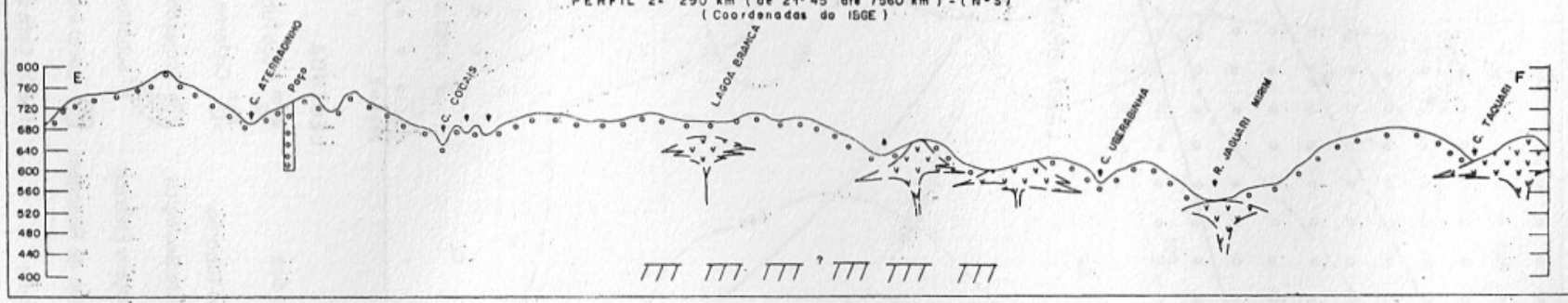

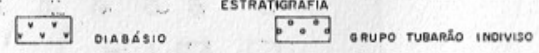

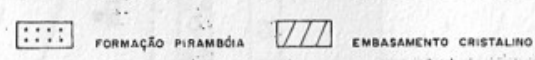
Escoin norizontol
Escola vertical

$=-7$, gommağa conumbatai 
Rev. IG, São Paulo, 3(1):15-23, jan./jun. 1982
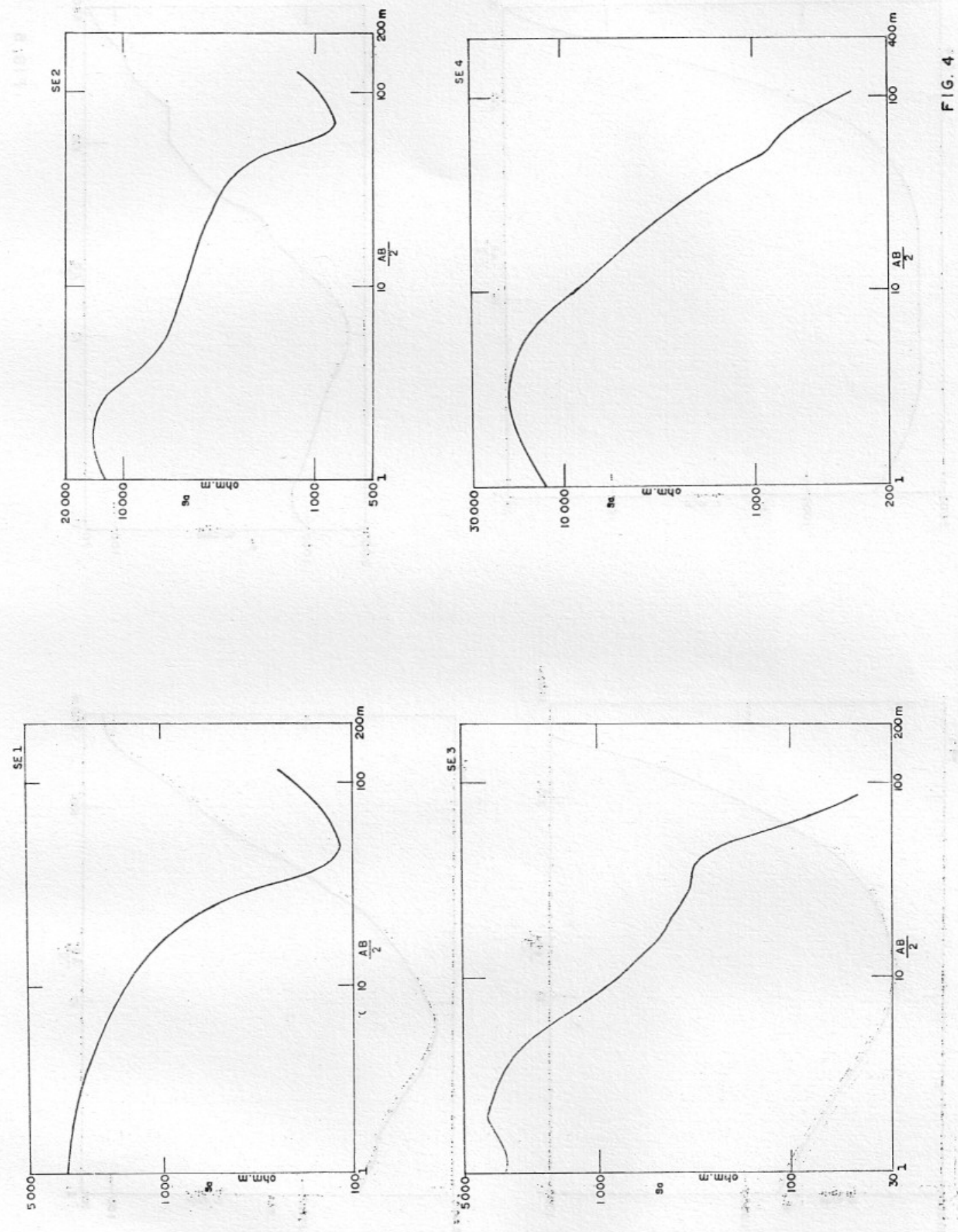
Rev. IG, São Paulo, 3(1):15-23, jan./jun. 1982
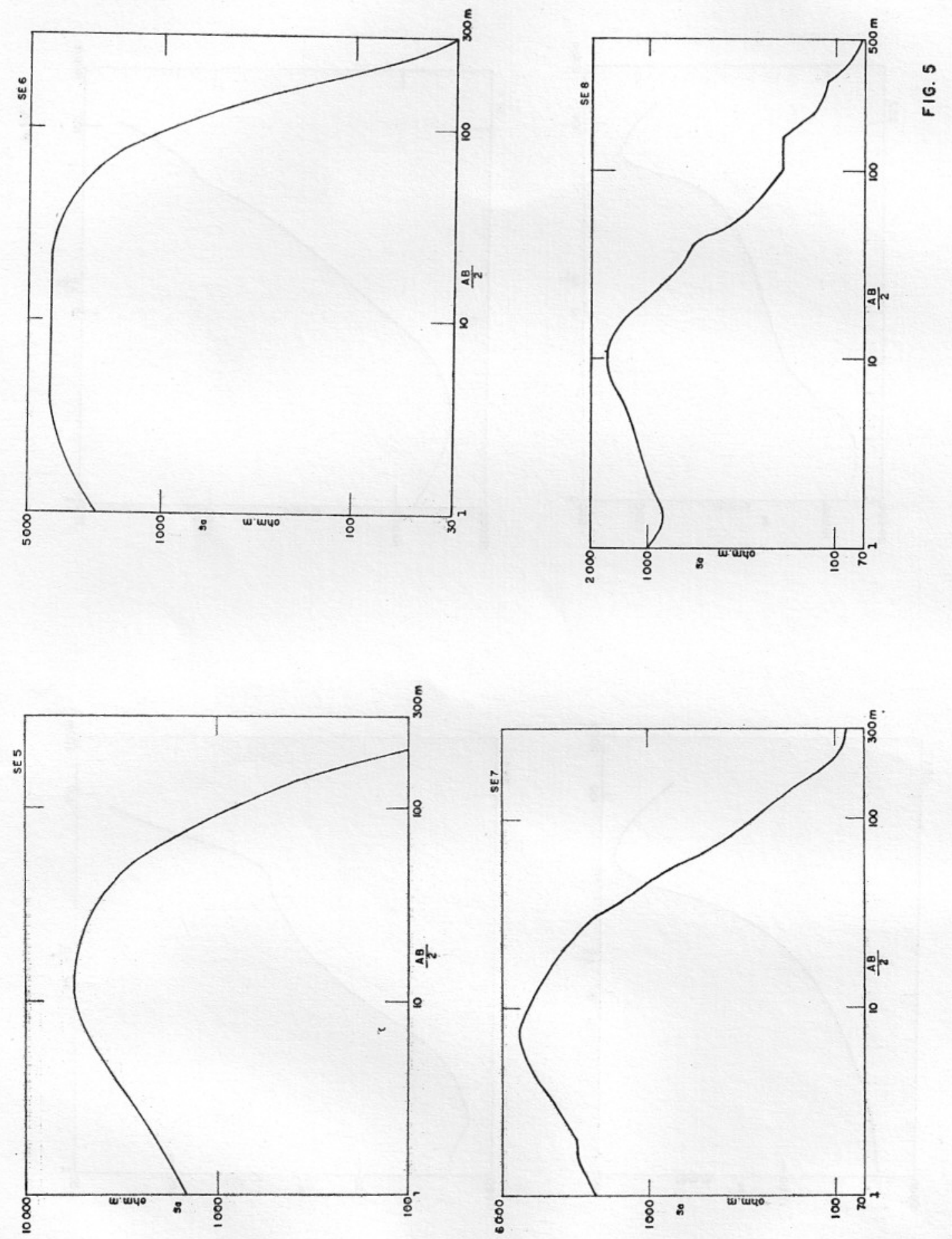


\section{REFERÊNCIAS BIBLIOGRÁFICAS}

ALMEIDA, F.F.M. de - 1954 - Geologia do Centro-Leste Mato-Grossense. Rio de Janeiro, DNPM, Divisão de Geologia e Mineralogia. 97p. (Boletim, 150)

\& BARBOSA, O. - 1953 - Geologia das quadrículas de Piracicaba e Rio Claro, Estado de São Paulo. Rio de Janeiro, DNPM, Divisão de Geologia e Mineralogia. 96p., 2 folhas geol. (Boletim, 143)

BJORNBERG, A.J.S. et a!ii - 1965 - Indícios de contribuição eólica nos sedimentos do Grupo Tubarão, em Limeira e Casa Branca, São Paulo. São Carlos, Escola de Engenharia de São Carlos, USP. p.1-16. (Geologia, 13 - Publicação EESC, 135)
DAVINO, A. - 1980 - O eacólito de diabásio de Tambaú. Determinação por sondagem elétrica. In: CONGRESSO BRASILEIRO DE GEOLOGIA, 31. ${ }^{\circ}$, Balneário de Camboriú, SC. Anais. Balneário de Camboriú, SC., So. ciedade Brasileira de Geologia. v.5 p.2583. 2589 .

FIORI, A.P. \& LANDIM, P.M.B. - $1980-$ Estratigrafia do Grupo Tubarão, Formação Aquidauana na região sudoeste do Estado de Minas Gerais. An. Acad. Brasil. Ciênc., Rio de Janeiro, 52 (1):109.124.

MEZZALIRA S. \& TORRES, C.C. - $1977-$ Águas subterrâneas no Estado de São Paulo; I Comportamento hidrogeológico das formações geológicas do Estado de São Paulo. São Paulo, Instituto Geológico. p.5-44. (Boletim, 2) 